\title{
Effects of metformin in reducing insulin resistance and reversing gonadotrophin levels (LH, FSH) followed by ovulation induction in infertile women with polycystic ovarian syndrome
}

\author{
Parul Jahan ${ }^{1}$, Abu S M Giasuddin ${ }^{1}$, Abu M M Haq ${ }^{1}$ \\ Sri Lanka Journal of Obstetrics and Gynaecology 2011; 33: 98-103
}

\begin{abstract}
Objectives: To evaluate the effectiveness of metformin in reducing insulin resistance, reversing the LH:FSH and followed by ovulation induction in infertile Bangladeshi patients with polycystic ovarian syndrome (PCOS).

Materials and methods: Cases were infertile patients with PCOS $(n=35$, age range - 18-35 years/Mean, age $\pm S D-25.68 \pm 3.81$ years, infertility - 1.5-10.0 years, Mean \pm SD $-4.12 \pm 1.21$ years) obtained from OG-OPD at MCW\&H, Dhaka. Infertile Bangladeshi couples without PCOS $(n=30)$ were included as controls. After fasting blood samples were collected at inclusion $\left(\right.$ PCOS- $\left.\mathrm{I}^{\circ}\right)$, metformin was prescribed (850 $\mathrm{mg} \mathrm{bd}$ ) and they were followed up after 2 months when fasting blood samples were taken again $\left(\mathrm{PCOS}-\mathrm{II}^{\circ}\right)$. Blood levels of glucose, insulin, insulin resistance (HOMA-IR), LH, FSH and LH:FSH were measured by standard laboratory methods. The patients were then given letrozole (aromatase inhibitor) (5 mg daily for 5 days from 2 nd day of cycle) and were continued for 3 consecutive cycles for pregnancy.
\end{abstract}

Results: Raised levels of insulin and HOMA-IR in PCOS-I $\mathrm{I}^{\circ}$ were reduced significantly by metformin treatment $\left(\mathrm{PCOS}-\mathrm{I}^{\circ}\right.$ vs $\mathrm{PCOS}-\mathrm{II}^{\circ}$ $\mathrm{P}<0.001$ ), but not to the control levels. Similarly, the elevated levels of LH, FSH and LH:FSH were lowered significantly $\left(\mathrm{PCOS}^{\circ} \mathrm{I}^{\circ}\right.$ vs PCOS-II ${ }^{\circ}$ $\mathrm{P}<0.001$ ), but again not to the full extent of control levels. Only $12 / 35$, i.e. $34.28 \%$ patients became pregnant after 3 months of letrozole treatment. Of the $12(34.28 \%)$ pregnancy positive patients, $5(14.28 \%)$ and $7(20 \%)$ were obese and non-obese respectively which was not statistically different $(\mathrm{P}>0.25)$.

\footnotetext{
${ }^{1}$ Medical College for Women and Hospital, Dhaka, Bangladesh.

Correspondence: Abu S M Giasuddin

E-mail: medicalcollegeforwomen@yahoo.com
}

\begin{abstract}
Conclusions: In $34.28 \%$ of the PCOS patients, insulin resistance and LH:FSH could be corrected and a successful conception was achieved by letrozole. In rest of the cases some other factors may be involved which could not be addressed by letrozole alone.
\end{abstract}

Key words: PCOS, metformin, insulin resistance, FSH, LH.

\section{Introduction}

Polycystic ovarian syndrome (PCOS) is one of the most common reproductive endocrinopathies affecting approximately $4-12 \%$ of women of reproductive age ${ }^{1,2}$. PCOS is characterized by multiple small cysts within the ovary and by excess androgen production from the ovaries and to a lesser extent from the adrenals ${ }^{1,2,3}$. Whether the basic defect is in the ovary, adrenal, pituitary or a more generalised metabolic defect, however, remains unknown $n^{3}$. PCOS usually presents with acne, hirsutism, amenorrhoea/oligomenorrhoea, infertility and obesity in young women ${ }^{3}$. Anovulation underlies the menstrual disorders of PCOS, which may present as amenorrhoea/oligomenorrhoea, dysfunctional uterine bleeding or infertility ${ }^{3}$. Ovarian ultrasound leading to the finding of polycystic ovaries confirms the diagnosis, although it will not be visualized on ultrasound examination in all women with $\mathrm{PCOS}^{1,2}$.

The absence of polycystic ovaries prompts laboratory testing. Hypersecretion of leutenizing hormone (LH) and mild hyper prolactinaemia are consistent and common in PCOS leading to altered ratio of LH to follicle stimulating hormone (FSH). Elevated plasma testosterone (TEST) and dehydroepiadrosterone-sulphate (DHEAS) in PCOS reflects increased androgen production leading to hirsutism. Therefore, a variety of laboratory investigations are made in patients with PCOS, particularly measurements of gonadrotrophins (LH, FSH) are often performed, with a ratio of $\geq 2.0$ being suggestive of $\mathrm{PCOS}^{3}$. PCOS has an association with obesity and 
is linked to the insulin resistance syndrome (IRS), also known as metabolic syndrome ${ }^{3}$. IRS is strongly associated with PCOS as elevated insulin levels lead to increased androgen (male hormone) production. It is this androgen which is possibly responsible for acne and excess body hair and for prevention of the ovum from maturing in the ovaries leading to a failure to release an egg (ovum). Hyper secretion of androgen interferes folliculo-genesis, anovulation, and formation of small cysts. Insulin resistant patients are usually very resistant to respond to any ovulation inducing agents ${ }^{3}$.

Drugs which reverse the insulin resistance will improve the situation. Recent studies have reported that insulin sensitizers could influence the pathophysiology of PCOS, decreasing serum insulin levels and resulting in improvements in reproductive functions $s^{4,5}$. Among the insulin sensitizing drugs, metformin act by inhibiting hepatic glucose production, increasing the number of insulin receptors, directly increasing the activity of the enzyme aromatase, allowing muscle and adipose tissue to take glucose irrespective of insulin level and decreasing intestinal glucose absorption ${ }^{6}$. All these actions of metformin reduce blood glucose level which leads to reduced insulin and androgen secretion followed by normal follicogenesis, ovulation and restoring normal menstruation. Metformin takes about 6-12 weeks to have maximum effect on the ovary. Usual doses are 1500-2500 mg per day and minimum dose should be $500 \mathrm{mg}$ tds or $850 \mathrm{mg} \mathrm{bd}^{7,8}$.

Literature survey has indicated that no work have been done or reported along this line with Bangladeshi infertile patients with PCOS. We have therefore undertaken the present interventional prospective case control study in infertile Bangladeshi patients with PCOS with the objectives to evaluate the following: (i) Insulin resistance and its response to metformin; (ii) Reversal of the LH:FSH ratio by metformin; (iii) Efficiency of metformin for ovulation and conception. This study will reveal the effect of metformin in reducing insulin resistance and reversal of LH:FSH ratio in Bangladeshi infertile women with PCOS. The approval was obtained from the Ethical Review Committee of the Medical College for Women and Hospital (MCW\&H), Dhaka, Bangladesh prior to commencement of the study.

\section{Materials and methods}

Study design: A case-control prospective interventional study with $90 \%$ power at $5 \%$ significance; Study place: Medical Research Unit (MRU) and Obstetrics and Gynaecology Out-Patient Department (OPD-OG) at MCW\&H, Dhaka, Bangladesh; Study Period: June 2008 to June 2010; Study population: Case - 35 infertile women with PCOS, Control - 30 infertile women without PCOS.

Patients selection criteria: PCOS was diagnosed by Rotterdam criteria. The diagnosis of PCOS was based on the findings of at least two of the three features, i.e. oligomenorrhoea (fewer than two cycles per year) with anovulation, bilateral enlarged polycystic ovaries (PCO) determined by ultrasonography (USG) and features (clinical or biochemical) of hyper-androgenism ${ }^{6,7,9,10}$. Infertility evaluation workup included: medical history of both partners, physical examination, husbands semen analysis, documentation of ovulation by TVS and mid luteal serum progesterone, USG of pelvic organ, HSG for tubal patency, TSH - to exclude hypothyroidism, OGTT.

Exclusion criteria: They included contraindications to metformin use within the previous 4 months. None of the women had thyroid dysfunction, hyperprolactinemia and diabetes mellitus. The women taking medication known to affect weight loss, gonadal or adrenal function, or carbohydrate or lipid metabolism were also excluded ${ }^{7,8}$.

\section{Patients and treatment protocol}

The prospective patient group comprised 35 consecutive infertile Bangladeshi patients with PCOS. After obtaining consent, the patient's proforma was completed and a $10 \mathrm{ml}$ aliquote of fasting (8-10 hours) blood was taken from each patient at inclusion $\left(\operatorname{PCOS}-\mathrm{I}^{\circ}\right)$. Then the patients were prescribed metformin $(850 \mathrm{mg}$ bd), followed up for up to 2 months, clinically evaluated according to standard criteria and blood specimen (fasting) taken from each patient at the end of 2 months follow-up period (PCOS- $\left.\mathrm{II}^{\circ}\right)$. These patients $\left(\mathrm{PCOS}-\mathrm{II}^{\circ}\right)$ were then given ovulation induction drug letrozol (aromatase inhibitor) (5 mg daily for 5 days from 2nd day of cycle) and followed up for another 3-6 months for conception.

\section{Control subjects}

A group of ovulatory partners of 30 infertile couples without PCOS, matched for age, were included in the study as control subjects. A $10 \mathrm{ml}$ aliquout of fasting (8-10 hours) blood were also obtained from each control after consent. 
Table. Laboratory parameters in patients and controls and their statistical analysis

\begin{tabular}{|c|c|c|c|c|c|c|}
\hline \multirow[t]{2}{*}{ Subjects* } & \multicolumn{6}{|c|}{ Laboratory parameters and their statistical analysis* } \\
\hline & $\begin{array}{c}\text { Glucose } \\
(\mathrm{mmol} / \mathrm{L})\end{array}$ & $\begin{array}{l}\text { Insulin } \\
(\mu \mathrm{IU} / \mathrm{ml})\end{array}$ & HOMA-IR & $\begin{array}{c}L H \\
(\mathrm{mIU} / \mathrm{ml})\end{array}$ & $\begin{array}{c}F S H \\
(m I U / m l)\end{array}$ & LH:FSH \\
\hline \multicolumn{7}{|l|}{ Controls } \\
\hline Number (n) & 30 & 30 & 30 & 30 & 30 & 30 \\
\hline Observed range & $3.6-6.1$ & $4.31-10.41$ & $0.62-2.07$ & $5.42-12.94$ & $8.73-15.76$ & $0.52-0.98$ \\
\hline Mean $\pm S D$ & $4.75 \pm 0.61$ & $7.65 \pm 1.45$ & $1.32 \pm 0.51$ & $9.54 \pm 1.56$ & $11.15 \pm 1.82$ & $0.69 \pm 0.13$ \\
\hline $95 \%$ range & $3.53-5.97$ & $4.75-10.38$ & $0.31-2.34$ & $6.42-12.66$ & $7.51-14.79$ & $0.43-0.95$ \\
\hline \multicolumn{7}{|l|}{ PCOS-I $^{\circ}$} \\
\hline Number(n) & 35 & 35 & 35 & 35 & 35 & 35 \\
\hline Observed range & $4.0-6.4$ & $14.35-30.64$ & $3.01-8.17$ & $16.53-35.42$ & $6.86-12.37$ & $20.5-2.79$ \\
\hline Mean $\pm S D$ & $5.11 \pm 0.71$ & $21.28 \pm 4.08$ & $5.14 \pm 1.42$ & $25.83 \pm 3.56$ & $10.72 \pm 1.61$ & $2.58 \pm 0.28$ \\
\hline $95 \%$ range & $3.69-6.53$ & $13.12-30.34$ & $2.31-7.98$ & 18.71-32.95 & $7.5-13.94$ & $2.02-3.14$ \\
\hline \multicolumn{7}{|l|}{ PCOS-II $^{\circ}$} \\
\hline Number (n) & 35 & 35 & 35 & 35 & 35 & 35 \\
\hline Observed range & $4.4-6.2$ & $9.21-17.61$ & $2.23-4.21$ & $9.95-16.13$ & $7.37-13.34$ & $1.02-1.49$ \\
\hline Mean $\pm S D$ & $5.09 \pm 0.45$ & $12.85 \pm 1.51$ & $2.93 \pm 0.61$ & $12.52 \pm 2.01$ & $9.85 \pm 1.51$ & $1.19 \pm 0.16$ \\
\hline $95 \%$ range & $4.19-5.99$ & $9.83-15.87$ & $1.71-4.14$ & $8.51-16.54$ & $6.82-12.86$ & $0.87-1.51$ \\
\hline \multicolumn{7}{|l|}{ Student's t-test } \\
\hline \multicolumn{7}{|c|}{ Control vs PCOS-I ${ }^{\circ}$} \\
\hline $\mathrm{t}:$ & -0.288 & 3.512 & -3.498 & -3.939 & 1.291 & -4.512 \\
\hline df: & 63 & 63 & 63 & 63 & 63 & 63 \\
\hline $\mathrm{p}:$ & $>0.5$ & $<0.001$ & $<0.001$ & $<0.001$ & $>0.200$ & $<0.001$ \\
\hline \multicolumn{7}{|c|}{ Control vs PCOS-II ${ }^{\circ}$} \\
\hline $\mathrm{t}:$ & -0.281 & -2.212 & -2.019 & -2.012 & 1.671 & 2.101 \\
\hline df: & 63 & 63 & 63 & 63 & 63 & 63 \\
\hline $\mathrm{p}:$ & $>0.5$ & $<0.05$ & $<0.05$ & $<0.05$ & $>0.100$ & $<0.05$ \\
\hline \multicolumn{7}{|l|}{ Paired t-test } \\
\hline \multicolumn{7}{|c|}{ PCOS$^{\circ} \mathrm{I}^{\circ}$ vs PCOS-II ${ }^{\circ}$} \\
\hline $\mathrm{t}:$ & 0.262 & 2.789 & 2.115 & 2.159 & 0.823 & 2.782 \\
\hline df: & 34 & 34 & 34 & 34 & 34 & 34 \\
\hline $\mathrm{p}:$ & $>0.5$ & $<0.01$ & $<0.05$ & $<0.05$ & $>0.400$ & $<0.01$ \\
\hline
\end{tabular}

*PCOS-I ${ }^{\mathrm{o}}$ : patients at inclusion;

PCOS-II $\mathrm{I}^{\circ}$ p patients at the end of 2 months follow up period at which time given letrozole for ovulation;

$\mathrm{P} \leq 0.05$ : significant;

$\mathrm{P}>$ 0.05: not significant. 


\section{Blood specimen and laboratory parameters}

Plasma and serum specimens from controls, PCOS- $\mathrm{I}^{\circ}$ and PCOS-II $\mathrm{II}^{\circ}$ subjects were analysed for the same laboratory parameters of research interest.

Serum levels of insulin $(\mu \mathrm{IU} / \mathrm{ml}), \mathrm{LH}(\mathrm{mIU} / \mathrm{ml})$ and FSH $(\mathrm{mIU} / \mathrm{ml})$ were quantitatively determined by commercially available test kits based on solid phase enzyme immunoassays (FSH-EIA test kit: Catalog No. 1001; LH-EIA Test Kit: Catalog No. 1004; Insulin-EIA Test Kit: Catalog No. 1009) from Lusys Laboratories Inc., San Diego, CA 92121, USA. The assay sensitivities, i.e. minimum detectable limits, were $2.0 \mu \mathrm{IU} / \mathrm{ml}, 2.0 \mathrm{mIU} / \mathrm{ml}$ and $2.5 \mathrm{mIU} / \mathrm{ml}$ for insulin, LH and FSH respectively. Fasting plasma glucose ( $\mathrm{mmol} / \mathrm{L})$ was determined by glucose $(\mathrm{mmol} / \mathrm{L})$ oxidase method spectophortometrically. Homeostasis model assessment of insulin resistance (HOMA-IR) was calculated using the formula: Fasting serum insulin $(\mu \mathrm{lU} / \mathrm{ml}) \times$ fasting plasma glucose $(\mathrm{mmol} / \mathrm{L}) /$ $22^{56,7,9}$.

\section{Statistical analysis}

Data were analysed statistically using Students t-test, Paired t-test and Chi-squared $\left(\chi^{2}\right)$ test. The Pvalues $\leq 0.05$ and $>0.05$ were considered significant and not significant respectively ${ }^{11}$.

\section{Results}

\section{Clinical findings}

The 35 PCOS patients had age range: 18.0-35.0 years with Mean $\pm S D$ : $25.68 \pm 3.81$ years. In these patients the range of duration of subfertility was 1.510.0 years with Mean $\pm S D: 4.12 \pm 1.21$ years. All of them had PCO by USG and oligomenorrhoea. The 30 control subjects had age range: $19.0-28.0$ years with Mean \pm SD: $23.14 \pm 1.81$ years. In the controls, the range of duration of subfertility was 2.0-10.0 years with Mean \pm SD: $4.34 \pm 1.32$ years. All the controls had no PCO by USG and had subfertility due to reasons other than PCO.

\section{Laboratory findings}

The results of laboratory investigations and their statistical analysis, i.e. blood levels of glucose ( $\mathrm{mmol} /$ $\mathrm{L})$, insulin $(\mu \mathrm{IU} / \mathrm{ml})$, HOMA-IR, LH $(\mathrm{mIU} / \mathrm{ml}), \mathrm{FSH}$ $(\mathrm{mIU} / \mathrm{ml})$ and LH:FSH ratio in controls, PCOS- $\mathrm{I}^{\circ}$, PCOS-II ${ }^{\circ}$ are stated in the Table. The significantly raised levels of insulin and HOMA-IR in PCOS- $\mathrm{I}^{\circ}$ were reduced significantly by metformin treatments (PCOS$\left.\mathrm{II}^{\circ}\right)$ but not to the control levels. Similarly, the significantly elevated levels of LH, FSH and LH:FSH ratio in $\mathrm{PCOS}-\mathrm{I}^{\circ}$ were lowered significantly by metformin treatment $\left(\mathrm{PCOS}-\mathrm{II}^{\circ}\right)$, but not to the full extent of control levels.
Only $12(34.28 \%)$ out of 35 PCOS patients were positive for ovulation induction/pregnancy at 2 months of letrozole treatment. In PCOS-II ${ }^{\circ}$ patients, the elevated levels (Mean $\pm S D$ ) of insulin, HOMA-IR, $\mathrm{LH}, \mathrm{FSH}$, and LH:FSH ratio in ovulation positive $(+v e, n=12)$ and ovulation negative (-ve, $n=23)$ cases were similar statistically ( $>0.2)$ [Ovulation (+ve) $\rightarrow$ Insulin: 11.35 \pm 2.25 , HOMA-IR: 3.06 $\pm 0.72, \mathrm{LH}: 11.73$ \pm 1.95 , FSH:9.71 \pm 1.36 , LH:FSH ratio: $1.22 \pm 0.14$; Ovulation (-ve) $\rightarrow$ Insulin:13.21 \pm 2.45 , HOMA-IR: $3.03 \pm 0.82, \mathrm{LH}: 12.38 \pm 2.01, \mathrm{FSH}: 10.53 \pm 1.45$, LH:FSH ratio: $1.26 \pm 0.16]$. Of the $12(34.28 \%)$ ovulation induction/pregnancy positive $\mathrm{PCOS}-\mathrm{II}^{\circ}$ patients, 5 $(14.28 \%)$ and $7(20 \%)$ were obese and non-obese respectively, which was not significantly different $\left(\chi^{2}=0.4502, \mathrm{df}=1, \mathrm{P}>0.25\right)$.

\section{Discussion}

Although PCOS was first described long ago in 1935 by Stein and Leventhal, its primary actiology and pathophysiological mechanism remain unclear. In the present study, our findings confirmed the biochemical features of high insulin resistance (HOMA-IR) with higher insulin levels, higher LH with normal FSH levels and higher LH/FSH ratio in $\operatorname{PCOS}^{7,8,12}$.

Metformin is a safe and effective drug used for the treatment of $\mathrm{PCOS}^{7,9}$. Administration of metformin improves the clinical and biochemical features and induces ovulation/pregnancy in PCOS. However, our findings showed that metformin is effective in reducing insulin levels and HOMA-IR partially, as these features did not reach to the control levels. Insulin resistance with elevated insulin level induces many unfavourable changes such as hyperandogenemia. This has the strongest association with insulin resistance which is most likely responsible for clinical features of oligomenorrhoea, hirsutism, etc, in $\operatorname{PCOS}^{12,13,14,15}$. It is generally accepted that testosterone is the measurement of choice for the investigation of female hyperandrogenism. Total testosterone is not, however, invariably elevated as contradictory results on increase in serum total testosterone in $30 \%$ to $70 \%$ patients with PCOS were reported ${ }^{12,16}$

In the present study, we observed also the presence of other important biochemical features commonly found in PCOS, i.e. increased LH level with normal or low FSH level leading to elevated LH/FSH ratio. Metformin treatment once again showed effectiveness in reversing the LH/FSH ratio by reducing LH levels, but did not show any effect on FSH level. The reduced LH level as well as LH/FSH ratio were still significantly higher in PCOS-II ${ }^{\circ}$ than 
control (Table). This means that metformin could not reverse the $\mathrm{LH} / \mathrm{FSH}$ ratio to the full extent to control level ${ }^{12}$. Despite these partial but significant reversal of HOMA-IR and LH/FSH ratio, pretreatment with metformin led to ovulation induction/pregnancy by letrozole in $12 / 35(34.28 \%)$ PCOS patients. Interestingly, we found no difference between obese $(5 / 12=41.66 \%)$ and non-obese $(7 / 12=58.44 \%)$ PCOS patients regarding ovulation induction/pregnancy $(P>0.25)$, although variable outcomes were reported $^{7,17,18}$.

The mode of action of metformin is possibly far more complex than originally envisaged. HOMA-IR, i.e. insulin resistance, is itself quite complex and leads to a variety of metabolic changes. It is also highly interrelated with $\mathrm{LH} / \mathrm{FSH}$ ratio through female hyperandogenism, particularly testosterone ${ }^{12,16}$. In recent years, a gonadal dysfunction secondary to a regulatory breakdown in the hypothalamic-pituitary axis was hypothesized. Now, there is a consensus that the key features in PCOS include insulin resistance, androgen excess and abnormal gonadotrophin dynamics. But it is unlikely that any one cause in isolation is responsible for this heterogeneous defect. Whatever the cause in addition to ovarian dysregulation, the adrenal, pituitary, and adipose tissue are implicated leading to a wide range of associated hormonal imbalances resulting in a disturbance in the secretion of the dominant follicle and hence anovulation ${ }^{9,12,13}$.

The discovery and characterization of a myriad of other adipose tissue - derived hormones and bioactive peptides collectively designated as adipokines have made the aetiopathogenesis of PCOS even more complex ${ }^{19,20}$. Among them, resistin, leptin, tumour necrosis factor-alpha (TNF- $\alpha$ ), etc may have important links with insulin resistance, hyperandrogenism and PCOS $12,13,21,22$. The serum levels of these adepokines such as leptin, resistin and TNF- $\alpha$ were not known in our patients which need to be given serious consideration.

Further, a susteptibility gene region has been identified on chromosome 19p13.2 close to the insulin receptor gene ${ }^{23,24}$. The single neucleotide polymorphisms (SNPs) of CYP19 gene, particularly SNPrs2414096, has been recently reported to be associated in the aetiopathogenesis of PCOS. Whether this SNP is a direct causal factor or it is a parallel phenomenon due to linkage disequilibrium with other genetic mutations was not mentioned ${ }^{25}$. It is suggested that the AA genotype of the SNP of rs2414096 in CYP19 gene could affect the function of acromatase and contribute in the aetiopathogenesis of PCOS in adolescence which is the key stage of the development of PCOS. The aromatase is closely associated with the concentration of androgen and it is very important for the development of ovary during the adolescence ${ }^{25}$.

\section{Conclusions}

Aetiopathogenesis of PCOS is complex, multifactorial and still poorly understood. To our knowledge, the present study was the first report showing elevated levels of HOMA-IR and LH/FSH ratio in Bangladeshi patients with PCOS. Although these levels were lowered with metformin therapy but not to the full extent of control levels, 12/35 (34.28\%) PCOS patients had ovulation induction/pregnancy. For anovulation in our remaining 23/35 (65.72\%) PCOS patients, some other factors are probably responsible. The adepokines such as leptin, resistin, TNF- $\alpha$ may also be important factors in PCOS to be considered in future investigations. Further studies involving larger number of PCOS patients with longer follow up period are warranted. Secondly, genetic studies are required to establish the occurance of SNPs of CYP19 gene, particularly SNPrs2414069, for its involvement in the aetiopathogenesis of PCOS in Bangladeshi patients as reported in other populations ${ }^{23,24,25}$.

\section{Acknowledgments}

This research work was carried out at the Medical Research Unit (MRU) set up by the Medical and Health Welfare Trust (MHWT), Uttara Model Town, Dhaka-1230, Bangladesh. The authors gratefully acknowledge MHWT for the financial support of the project. Also, the authors would like to thank Mr. MH Khan, Biochemist, for laboratory assistance and Mr. Moniruzzaman Khan, Assistant Programmer, MCW\&H, Uttara Model Town, Dhaka-1230 for internet browsing and composing the manuscript.

\section{References}

1. Balen AH. Secondary amenorrhoea. In: Edmonds DK. (Editor). Dewhurst's Textbook of Obstetrics and Gynaecology for Postgraduates, Sixth Edition (Reprinted); Oxford: Blackwell Science Ltd; 2002: 42-60.

2. Bhatla N. Amenorrhoea, hypomenorrhoea and oligomenorrhoea. In: Bhatla N (Editor). Jeffcoat's Principles of Gynaecology, International Edition (Fifth Edition); London: Arnold; 2001: 541-59.

3. Kauffman RP, Baker VM, Dimarino P, Gimpel T, Castracane VD. Polycystic ovarian syndrome and insulin resistance in white and Mexican American women: a comparison of two distinct populations. Am J Obstet Gynecol 2002; 187(5): 1362-69.

4. Alper T, Kahraman H, Cetinkaya MB, Yanik F, AKcay G, Bedir A, et al. Serum leptin and body composition in polycystic ovarian syndrome. Ann Saud Med 2004; 24(1): 9-12. 
5. Kowalska I, Kinalski M, Straczkowski M, Wolezyski S, Kinaslka I. Insulin, leptin, IGF-I and insulin dependent protein cencentrations after insulin-sensitizing therapy in obese women with polycystic ovary syndrome. Eur J Endocrinol 2001; 144: 509-15.

6. Harborne LR, Sattar N, Norman JE, Fleming R. Metformin and weight loss in obese women with polycystic ovarian syndrome: comparison of doses. J Clin Endocrinol Metab 2005; 90(8): 4593-98.

7. Palomba S, Orio F Jr, Falbo A, Manguso F, Russo T, Cascella $\mathrm{T}$, et al. Prospective parallel randomized, double-blind, double-dummy controlled clinical trial comparing clomiphene citrate and metformin as the first-line treatment for ovulation induction in nonobese anovulatory women with polycystic ovary syndrome. J Clin Endocrinol Metab 2005; 90(7): 4068-74.

8. Lord JM, Flight IH, Norman RJ. Metformin in polycystic ovary syndrome: systematic review and meta-analysis. $\mathrm{Br}$ Med J 2003; 327: 951-53.

9. Kashyap S, Wells GA, Rosenwaks Z. Insulin-sensitizing agents as primary therapy for patients with polycystic ovarian syndrome. Hum Reprod 2004; 19: 2474-83.

10. Homburg R. What is polycystic ovarian syndrome? A proposal for a consensus on the definition and diagnosis of polycystic ovarian syndrome. Hum Reprod 2002; 17: 249599.

11. Kirkwood BR. Essentials of Medical Statistics, First Edition (Reprinted); Oxford: Blackwell Scientific Publications; 2003.

12. Wallace AM, Sattar N. The changing role of the clinical laboratory in the investigation of polycystic ovarian syndrome. Clin Biochem Rev 2007; 28: 79-92.

13. Galluzzo A, Amato MC, Giordano C. Insulin resistance and polycystic ovarian syndrome. Nutr Metab Cardiovasc Dis 2008; 18: 511-18.

14. Macut D, Panidis D, Glisi B, Spanos N, Petakov M, Bjekic $\mathrm{J}$, et al. Lipid and lipoprotein profile in women with polycystic ovary syndrome. Can J Physiol Pharmacol 2008; 86: 199-204.
15. Lindholm A, Andersson LO, Eliasson M, Bixo M, Sundström-Poromaa I. Prevalence of symptoms associated with polycystic ovary syndrome. Int J Gynaecol Obstet 2008; 102: $39-43$.

16. Burger HG. Androgen production in women. Fertil Steril 2002; 77 (Suppl 4): S3-5.

17. Fleming R, Hopkinson ZE, Wallace AM, Greer JA, Sattar N. Ovarian function and metabolic factors in women with oligomenorrhoea treated with metformin in a randomized double blind placebo-controlled trial. J Clin Endocrinol Metab 2002; 87: 569-74.

18. Maciel GA, Soares Junior JM, Alves da Motta EL, Abi Haidar M, De Lima AR, Baracat EC. Nonobese women with polycystic ovary syndrpome respond better than obese women to treatment with metformin. Fertil Steril 2004; 82: 355-60.

19. Alzahrani AS. Resistin: can we resit its role in insulin resistance? Ann Saudi Med 2005; 25(4): 281-82.

20. Kershaw EE, Flier JS. Adipose tissue an endocrine organ. J Clin Endocrinol Metab 2004; 89: 2548-56.

21. Al-Herithy RN, Al-Ghamdi S. Serum resistin, adiposity and insulin resistance in Saudi women with type 2 diabetes mellitus. Ann Saudi Med 2005; 25(4): 283-87.

22. Chae SJ, Kim JJ, Choi YM, Hwang KR, Jee BC, Ku SY, et al. Clinical and biochemical characteristics of polycystic ovarian syndrome in Korean women. Hum Reprod 2008; 23: 192431.

23. Sam S, Dunaif A. Polycystic ovary syndrome. Trends Endocrinol Metab 2003; 8: 365-70.

24. Dunaif A. Hyperandogenemia is necessary but not sufficient for polycystic ovary syndrome. Fertil Steril 2003; 2: 262-63.

25. Jin J-L, Sun J, Ge H-J, Cao Y-X, Wu X-K, Liang F-J, et al. Association between CYP19 gene SNPrs2414096 polymorphism and polycystic ovary syndrome in Chinese women. BMC Med Gen 2009; 10: 139-43. (doi: 10.1186/ 1471-2350-10-139). 